\title{
REPRESENTACIONES DEL NO-LUGAR EN LOST IN TRANSLATIONY SOMEWHERE DE SOFÍA COPPOLA
}

Representations of non-places in Lost in Translation and Somewhere by Sofia Coppola

\author{
Stefano LlinÁs LAMBOGLiA ${ }^{a}$ \\ Universitat de Barcelona
}

DOI: $10.15366 /$ secuencias2020.51.003

\begin{abstract}
RESUMEN
Teorizando sobre la conceptualización cinematográfica del espacio, este trabajo pone bajo escrutinio dos largometrajes de la directora y guionista estadounidense Sofía Coppola, Lost in Translation (2003) y Somewhere (2010), para analizar las técnicas personales de la representación espacial y cómo éstas ayudan en el planteamiento ideológico y/o moral de la obra. Se relacionará el espacio fílmico con el espacio real, subrayando la diferencia entre la creación metódica del primero - la cual tiene el fin estético de paralelar o contrastar el ánima humana que lo transita - y la inabarcable existencia del segundo -que también resulta indiferente a sus ocupantes-. Tomando el concepto de «no-lugar» ideado por Marc Augé y ampliando su abanico de utilización al traerlo al campo del espacio representado de manera audiovisual, se discute cómo la acepción de este término puede concordar con la construcción del espacio fílmico llevada a cabo por la directora, ejemplificando con escenas y demás aspectos de cada filme en particular. Además, se aplican las ideas antropológicas de Manuel Delgado en la discusión sobre la posible filiación moral del espacio fílmico con la del espacio real, para finalmente adoptar el punto de vista sociológico a partir del trabajo de David Riesman en un intento por establecer la posibilidad de redención o apropiación del espacio por parte de los personajes de cada filme.
\end{abstract}

Palabras clave: no-lugar, Sofía Coppola, Marc Augé, cine americano, espacio

\begin{abstract}
By theorizing about the cinematic conceptualization of space, this article focuses on two feature films by American director and screenwriter Sofia Coppola, Lost in Translation (2003) and Somewhere (2010), with the intent of analyzing her own personal techniques of spatial representation and how these help in the ideological and/or moral setting of her work. This article will connect filmic space to real space, highlighting the difference between the methodical creation of the former - which has the aesthetic aim of mirroring or contrasting the human spirit that surpass it - and the unfathomable existence of the latter, which also ends up being indifferent towards its inhabitants. Taking Marc Augé's concept of «non-places» and expanding its range of application by bringing it to the field of spatial representation in audiovisual media, the article discusses how the meaning of this term can be consistent with the construction of filmic space orchestrated by Sofia Coppola, exemplifying with specific scenes and other aspects of each film in particular. Moreover, the anthropological ideas of Manuel Delgado are applied in the discussion about the possible moral filiation of filmic space versus that of real space, to finally take the sociological point of view with David Riesman's work in an attempt to establish the possibility of redemption or appropriation of space by the characters in each film.
\end{abstract}

Keywords: non-places, Sofia Coppola, Marc Augé, American cinema, space

[a] Stefano Llinás Lamboglia es escritor y académico literario, cursando (al día del presente escrito, 12 de septiembre de 2018) un Máster en Teoría de la literatura y literatura comparada en la Universitat de Barcelona. Cursó su primera licenciatura en los Estados Unidos de América, obteniendo un Bachelor of Fine Arts in Dramatic Writing con mención de honor Cum Laude. Ha publicado ficción en varias revistas electrónicas y un artículo académico en la revista de investigación sobre lo fantástico, Brumal, de la Universitat Autónoma de Barcelona. Es además un guionista premiado, habiendo obtenido el Silver Prize en la categoría Science Fiction del World Series of Screenwriting 2014. E-mail: stefano_llinas92@hotmail.com 
El espacio, esa dimensión de la realidad en la que nos desplazamos y existimos, ha sido desde tiempo inmemorial una parte clave en las representaciones pictóricas y narrativas de la humanidad, hasta tal punto que es imposible pensar en algún desarrollo diegético sin conjurar también el contexto espacial en el que ocurre. Podría decirse que esta dimensión de la realidad, que pasa a ser un elemento constructivo de la ficción, siempre ha sido considerada como un prisma o un conductor de la ideología subyacente a la historia que ocurre en él debido a su omnipresencia y obviedad, pero no ha sido sino hasta la Modernidad - segunda mitad del siglo XIX hasta el presente- cuando se han avanzado teorías sobre el rol y la importancia del espacio en la infraestructura de la sociedad (y del arte), luego de la consolidación de campos de estudio como la Sociología, la Filosofía y el Urbanismo.

En el meollo de estas consideraciones se encuentra la figura imponente de la ciudad, espacio que ha seducido a más de un teórico - recordemos brevemente a Georg Simmel y su famoso texto Las grandes urbes y la vida del espíritu ${ }^{1}$ gracias a su capacidad para albergar la gran mayoría de referentes socioculturales del desarrollo humano en su seno, en una extensa amalgama que podemos llamar «experiencia urbana». Hay que recordar, también, que esta experiencia urbana es una que no se ha dado antes en la historia y, por ende, está ligada intrínsecamente a los demás procesos de la Modernidad - el capitalismo avanzado, la especialización laboral, el individualismo, etc.- que se argumenta tienen un efecto alienante sobre el ciudadano. Como lo explica David Frisby:

La modernidad alberga una serie de tensiones que se manifiestan en forma de ambigüedades y contradicciones [...]. En apariencia, esos procesos crean modos de ordenamiento de la sociedad y sus estructuras. Sin embargo, este ordenamiento de las formaciones sociales va acompañado de procesos de desintegración de la experiencia humana, y crea así discontinuidades fundamentales en los ámbitos de la vida moderna ${ }^{2}$.

Son algunos de estos efectos alienantes o que despersonalizan al individuo urbano los que ocupan las siguientes páginas, tomando como objeto de escrutinio su manifestación en el cine, más específicamente, en dos filmes de la directora americana Sofía Coppola. El séptimo arte es el que más depende de la representación espacial para lograr un efecto de verosimilitud y su concreción narrativa; en su afán por crear un significado cognoscible por la audiencia, termina por sublimar de forma interpretativa la materia real de la que se ocupa, que en los casos de Lost in Translation (2003) y Somewhere (2010) son las grandes ciudades de Tokio y Los Ángeles, respectivamente -además de las experiencias de alienación, soledad y falta de propósito vital que sufren los personajes que habitan en ellas-.

Para mejor entender cómo se da esta representación del espacio en ese par de largometrajes, y para mejor establecer el punto argumentativo del trabajo, primero hay que ahondar en las ideas categóricas del sociólogo Marc Augé, cuya aproximación al estudio del espacio se centra en la dualidad lugar/no-
[1] Publicado en 1903. Sus ideas sobre el hombre y su relación con la ciudad fundaron la base sobre la cual otros teóricos citados en este trabajo han construido su propio entendimiento.

[2] David Frisby, Paisajes urbanos de la modernidad Exploraciones críticas (Buenos Aires, Prometeo Libros, 2007), p. 13. 
[3] Marc Augé, Non-lieux. Introduction à une anthropologie de la surmodernité, (París, Éditions du Seuil, 1992), p. 69. (La traducción es mía).

[4] Marc Augé, Non-lieux, p. 100. (La traducción es mía).

[5] (La cursiva es mía). Marc Augé, Non-lieux, pp. 100-101. (La traducción es mía). lugar, conceptos apropiados para el análisis de la visión coppoliana debido a su acertada delimitación de la funcionalidad de los espacios dentro del contexto de la sobremodernidad -tiempo en el que se desarrollan ambos filmes-. Augé nos define primero su concepto de lugares, los cuales, para él, tienen como esencia la interacción humana, los llama «lugares antropológicos»: «Esos lugares tienen al menos tres caracteres comunes. Los queremos identitarios, relacionales e históricos» ${ }^{3}$. El contenido de estos lugares antropológicos es tanto espacial como social, puesto que las personas que habitan el espacio crean o fundan su identidad a partir de las relaciones de coexistencia que en ellos se desarrollan. Por el contrario, «si un lugar se puede definir como identitario, relacional o histórico, un espacio que no se puede definir ni como identitario, ni como relacional, ni como histórico se definirá como un no-lugar» ${ }^{4}$. Los nolugares pasan a ser la antítesis de esos espacios donde la interacción humana tiene potencial para crear recuerdos sustanciales, relevantes para su concepto de «Yo» y para su red íntima de cambio interpersonal.

[...] La sobremodernidad es productora de no-lugares, es decir, de espacios que no son ellos mismos lugares antropológicos y que, contrariamente a la modernidad baudeleriana, no integran a los lugares antiguos: estos, quedando catalogados, clasificados o promovidos como «lugares de memoria», ocupan un sitio circunscrito y específico. Un mundo donde uno nace en clínicas y muere en hospitales, donde se multiplican, en modalidades lujosas e inhumanas, los puntos de tránsito y las ocupaciones provisorias (las cadenas de hoteles y los ocupantes ilegales, los clubs vacacionales, los campos de refugiados, los barrios marginales condenados al desguace o a una eternidad de podredumbre), donde se desarrolla una red apretada de medios de transporte que también son espacios habitados, donde el acostumbrado a los supermercados, a los cajeros automáticos y a las tarjetas de crédito reincide con gestos comerciales «inconscientes», un mundo así condenado a la individualidad solitaria, al tránsito, a lo provisorio y a lo efimero ${ }^{5}$.

Sería fácil decir, entonces, que la representación fílmica de la ciudad llevada a cabo por Coppola en sus dos películas hace gran uso de este entendimiento del espacio para, de cierto modo, conducir la exploración diegética de la alienación y la despersonalización; aunque sí es observable que los filmes están dotados de una intencionada construcción de psicología ambiento-espacial, esta consideración teórica llega a una conclusión diferente: los no-lugares representados en los filmes de Coppola no son, en últimas, la fuerza que engendra la alienación y la falta de propósito de los personajes principales, sino que funcionan meramente para exacerbar estos sentimientos preexistentes mediante procesos de despersonalización. En el caso de Lost in Translation, estos procesos incluyen la disminución de la cultura japonesa a una parodia de cordialidad excesiva y excentricidad cómica, la presentación panorámica de la ciudad como un ente inhóspito e indomable y la mistificación estética y desdeñosa del lenguaje japonés. En el caso de Somewhere, los procesos más pronunciados son la reducción del intercambio humano a su funcionalidad 
mercantil, la repetición abrumadora de lo cotidiano y la ilusoria prolongación del tiempo que tiene como resultado el apogeo del ocio y los vicios. Es decir, los personajes no sufren de angustias existenciales por habitar el espacio, sino por la discordancia entre sus ambiciones y su capacidad para realizarlas. El espacio fílmico no es tanto determinante como lo es copartícipe.

¿Qué evidencia esta suposición? Entre otras cosas, está la naturaleza transitoria de la estadía en la institución hotelera - en partes iguales por todos los protagonistas-, la capacidad humana para crear vínculos así se esté habitando dentro o fuera de un no-lugar y el potencial de apropiación espacial que Coppola nos promete está siempre al alcance de la mano, así sea luego de una revelación tardía. La clave está en entender que el universo coppoliano abarca la emancipación, a pesar de preocuparse bastante por el vacío. En este cine «se trata de confiar en la capacidad activa y creativa del ser humano, en su potencial para apropiarse de sus condiciones de vida, reinterpretarlas, darles usos nuevos e inesperados: de habitar, en suma, incluso en los espacios despersonalizados de la sobremodernidad» ${ }^{6}$.

Hablando bajo el manto de la teoría cinematográfica, también podemos llegar a la misma conclusión teniendo en cuenta la naturaleza misma de la representación fílmica, que impone una funcionalidad narrativa a todo elemento que componga la imagen, como es mencionado por David Bordwell: «Como ya he dicho, todos los materiales cinematográficos funcionan de forma narrativa, no solo la cámara, sino el habla, los gestos, el lenguaje escrito, la música, el color, los procesos ópticos, la iluminación, el vestuario, incluso el espacio y el sonido en off ${ }^{\prime}$. Es más, la consideración del espacio fílmico como una construcción que acentúa su otra finalidad discursiva, nos acerca a la idea de que esa misma cualidad ficcional que lo define y le da su poder también lo destripa de su capacidad para afectar orgánicamente aquello que encierra. Hay que reiterar que este espacio no es el mismo que el espacio real del cual se nutre para existir - como una especie de palimpsesto hecho a retazos-, por lo cual no posee el mismo conjunto relacional de efectos psíquicos sobre el ser humano.

Gilles Deleuze avanzó la idea del espacio fílmico como «espace quelcon$q u e »$ ( «espacio cualquiera»), idea relacionada a la expuesta aquí, que propone el pensar en los espacios representados en el cine como aquellos que han perdido ante el ojo del espectador una relación totalitaria de su expansión, debido a la forma en que han sido presentados en el montaje y en los encuadres:

Un espacio cualquiera no es una abstracción universal, en todo momento, en todo lugar. Es un espacio perfectamente singular, que solamente ha perdido su homogeneidad; es decir, el principio de sus relaciones métricas o la conexión de sus propias partes, si bien los enlaces se pueden hacer de una infinidad de maneras. Es un espacio de conjunción virtual ${ }^{8}$.

Esto no quiere decir que el espacio fílmico sea estéril: al ser una representación intencionada, fragmentaria e imbuida de ánima narrativa, este espacio está perfectamente ensamblado para que una única historia sea resaltada en él. A
[6] José Antonio Cerrillo Vidal, «Cine y experiencia urbana contemporánea» (Aposta revista de ciencias sociales, $n .^{\circ} 43$, octubre, 2009), p. 7.

[7] (La cursiva es mía). David Bordwell, La narración en el cine de ficción (Barcelona, Paidós, 1996), p. 20.

[8] Gilles Deleuze, L'imagemouvement (París, Éditions de minuit, 1983), p. 155. (La traducción es mía). 
[9] Fabien Demangeot, «L'esthétique du vide dans le cinéma de Sofia Coppola» (Studia Universitatis Petru Maior - Philologia, vol. 19, 2015), p. 101. (La traducción es mía). pesar de admitir una infinitud de posibilidades imaginativas que intenten hacer de él una concreción conexa, el espacio fílmico - como todo otro elemento cinematográfico, en realidad- no posee esa indiferencia en su existir que el espacio real sí posee y que le brinda trascendencia; observación análoga a la de Demangeot sobre los personajes: «Los personajes de Sofía Coppola mueren al momento en que no hay más personas que los observen ${ }^{9}$. Viendo el espacio fílmico desde esta perspectiva, también podríamos llegar al mismo punto expuesto con anterioridad: el espacio sería cómplice de las intenciones narrativas en lugar de ser su productor, dado que su naturaleza compositiva está confinada a su funcionalidad y su creación está limitada y subordinada a la historia que ayuda a contar.

Pero ubicarnos en este ángulo no es la única manera de abordar el ejercicio teórico, ya que el hacerlo obviaría las minucias de los filmes de Coppola que nos interesan para ejemplificar la representación de los no-lugares en la pantalla grande. Antes de proseguir en el análisis de ciertas escenas, es necesario dar una idea generalizada de la temática y el transcurrir de eventos en los dos largometrajes, ideas que a su vez legitiman el enfoque teórico sobre el espacio fílmico, estando el desarrollo diegético ligado a la experiencia urbana. En Lost in Translation, segundo filme de la directora, somos testigos de la estadía de dos americanos en el hotel Park Hyatt de Tokio. Se trata de Bob Harris, un famoso y veterano actor que visita el Japón para grabar unos comerciales de güisqui, y de Charlotte, una joven recién graduada en Filosofía que acompaña a su esposo mientras este trabaja en la capital nipona. Ambos personajes comparten un núcleo de incertidumbre que termina por enlazar sus experiencias de la megaciudad asiática. En Somewhere, filme medianamente autobiográfico, seguimos la vida de Johnny Marco, un célebre actor de Hollywood que está aposentado en el Château Marmont, una residencia vacacional en Los Ángeles de cierto lujo y prestigio. Entre su tedio y soledad conocemos a su hija, Cleo, quien es dejada bajo su cuidado por un tiempo ambiguo - su relación es hasta ese momento de poca complicidad paterno-filial-. Junto a su hija, Johnny sigue su rutina de estrella de cine y revive la paternidad.

Para los que conozcan un poco de la vida de la directora, estas temáticas no sonarán tan lejanas, puesto que Coppola creció en el mundo de la industria cinematográfica y ha tenido que lidiar, a su propia manera, con las mismas cuestiones con las que lidian sus protagonistas. Regresando a Lost in Translation y a la ciudad de Tokio, podemos ver en las representaciones de esta urbe no solo una agudización de los no-lugares que forman su columna vertebral, que trae al frente la problemática de desplazarse constantemente a través de ellos, sino también un enfoque que, por momentos, reduce el cariz cultural japonés del espacio y de los habitantes (elemento inseparable y característico) a su índole como foráneo para la persona occidental promedio (por decirlo de alguna manera). En varias ocasiones se utiliza el acento de algunos personajes japoneses al hablar inglés como fuente de burla, lo que es un poco hipócrita, dado que aquellos han hecho un esfuerzo por sobrepasar los límites de su propia cultura, mientras que el filme en sí se sostiene sobre el hecho de que su audiencia ideal 
(anglosajones occidentales) no entienden en absoluto los diálogos y las imágenes del idioma japonés, ya que se contentan con su existencia monolingüe. $\mathrm{Y}$, aunque vale la pena mencionarlo, esta es solo una cuestión auxiliar.

¿Cuáles son, pues, los no-lugares representados en Lost in Translation? Son los que ocupan la mayor parte de la imagen a través de la película, como los lista Cerrillo Vidal: «Tokio parece estar constituida exclusivamente de no lugares: el hotel, el metro, la sala de videojuegos, el hospital, el tren, las carreteras, las grandes avenidas plagadas de símbolos publicitarios ${ }^{10}$. Con respecto al hotel, que es la ubicación central de la narrativa, es adecuado notar que las habitaciones de los personajes - más la de Charlotte que la de Bob - tienen aún potencial para crear significado, ya que «el cuarto de hotel es el espacio del "mundo personal" de los personajes, donde se localizan como sujetos, aunque sea transitoriamente» ${ }^{11}$. Es allí, tirados juntos en la cama, donde tienen la conversación más encarnada, la que más se ocupa de sus respectivas angustias. Ya habían entablado amistad y habían explorado partes de la ciudad juntos, pero es allí, en ese entorno recluido, donde revelan secretos íntimos. En contraposición, las demás áreas del hotel -con, tal vez, un par de excepciones mínimas- son inhóspitas en el sentido que no poseen fomento para la expresión sincera de problemáticas psíquicas; en esas áreas, todo queda a la merced de la cortesía. Además, cada interacción que viven en el vestíbulo del hotel es gobernada por intereses monetarios. Bob, sobre todo, es guiado por el espacio y abordado con una cordialidad que resulta un proceso de despersonalización (irónicamente). Esta es una gran diferencia en lo que concierne a las experiencias de Bob y Charlotte. «Bob es un actor famoso; Charlotte, una inmigrante desconocida. Él, donde quiera que transite, es siempre reconocido; ella circula anónima por los lugares» ${ }^{12}$.

Los no-lugares que son tratados con más sensibilidad estética por parte de la directora son los medios de transporte y las carreteras, en los cuales vemos una sobreabundancia de símbolos: esta sensibilidad se manifiesta en la parsimonia con la que son tratados aquellos espacios y en la nitidez con que se capturan; las vías públicas son los no-lugares que más detalles visuales le ofrecen al espectador. Tanto Charlotte como Bob son conscientes de la presencia de estos anuncios y cada uno tiene una forma personal de reaccionar ante
[10] José Antonio Cerrillo Vidal, «Cine y experiencia urbana contemporánea», p. 10.

[11] Denise Moraes Cavalcante, «Entre o hotel e a cidade: espaços em trânsito no filme Encontros e desencontros da diretora Sofia Coppola» (Comunicación: Revista Internacional de Comunicación Audiovisual, Publicidad y Estudios Culturales, $\mathrm{n} .^{\circ}$ 10, 2012), p. 416. (La traducción es mía).

[12] Denise Moraes Cavalcante, «Entre o hotel e a cidade: espaços em trânsito no filme Encontros e desencontros da diretora Sofia Coppola», p. 417. (La traducción es mía).
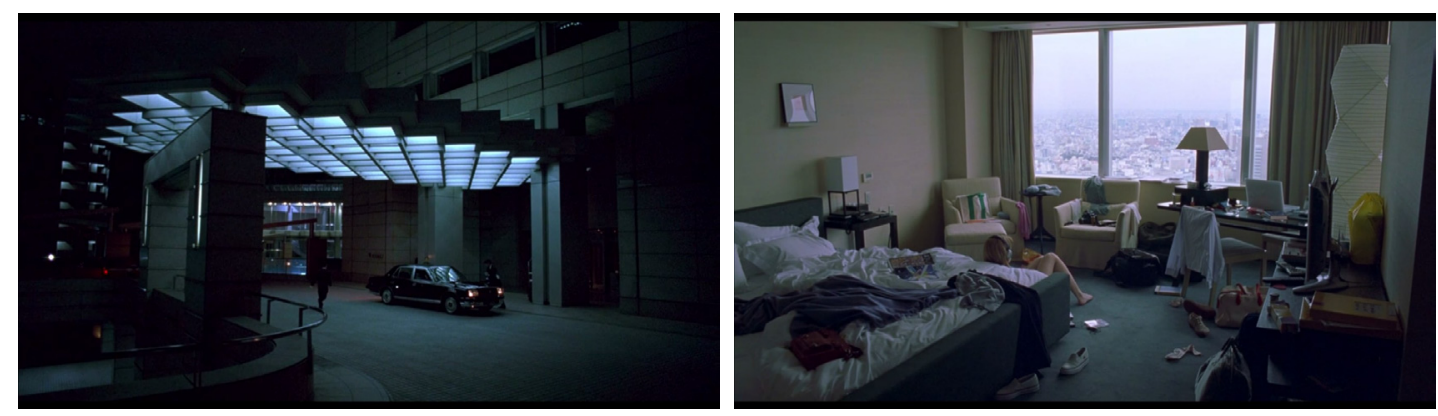

Lost in Translation (Sofia Coppola, 2003). Fotogramas de la entrada del hotel Park Hyatt de Tokio y de la habitación de Charlotte. 
ellos. Charlotte, siempre contemplativa ante la ciudad, incluso desde lo alto de la ventana de su habitación de hotel, pareciera sucumbir a la estimulación y se deja llevar por ella, mientras que Bob la observa distanciado, reconociéndola como una serie de entidades extranjeras a sí mismo. Esta actitud es, en efecto, la que tiene cada personaje cuando se relaciona con la cultura japonesa en general - con Charlotte un poco más dispuesta a adentrarse en ella, como vemos en su participación en el taller de ikebana, en su visita al templo de Kyoto, en sus caminatas entre la multitud-. «Durante sus excursiones, Charlotte mantiene una actitud contemplativa e indagadora, caminando y observando con atención todos aquellos lugares que visita. [...] Esa exploración externa por la ciudad es una metáfora de la exploración interna, de su identidad» ${ }^{13}$.

Precisamente gracias a la curiosidad de Charlotte, el filme logra llenar los intersticios representativos entre esa larga concatenación de no-lugares con espacios antropológicos para crear un contraste. El bar nocturno, el karaoke y el apartamento de los amigos de Charlotte sirven como ejemplo de lo que podría llegar a ser una experiencia real de la ciudad, una experiencia que no está limitada por relaciones mercantiles, sino por intercambio visceral y genuino entre personas que no esperan ganancia monetaria por el trato que dan. En una de esas salidas, Charlotte termina adentrándose en una gran sala donde hay una variedad de videojuegos de salón. He aquí lo que para mí es un ejemplo de lugar polivalente. En el contexto de la vida de Charlotte, quien no habla japonés y aún menos comprende los pormenores de la cultura (sobre todo la cultura juvenil), esta sala representa un no-lugar claro y conciso: no es posible para ella entablar relación con la gente ni actuar sobre el espacio sin alguna clase de objeto mediador. En cambio, en el contexto de los jóvenes que se encuentran en la actividad del juego, el espacio ya se encuentra apropiado, dispuesto a servir como conductor para la creación de sentido. Luego veremos en Somewhere que el juego es una actividad específica que sirve para apropiar el espacio hacia los intereses de los jugadores.

[13] Héctor Paz Otero, «El cine de Sofía Coppola: la deconstrucción de la mirada patriarcal» (Quaderns de cine, $\mathrm{n} .^{\circ} 5$, 2010), pp. 73-74.

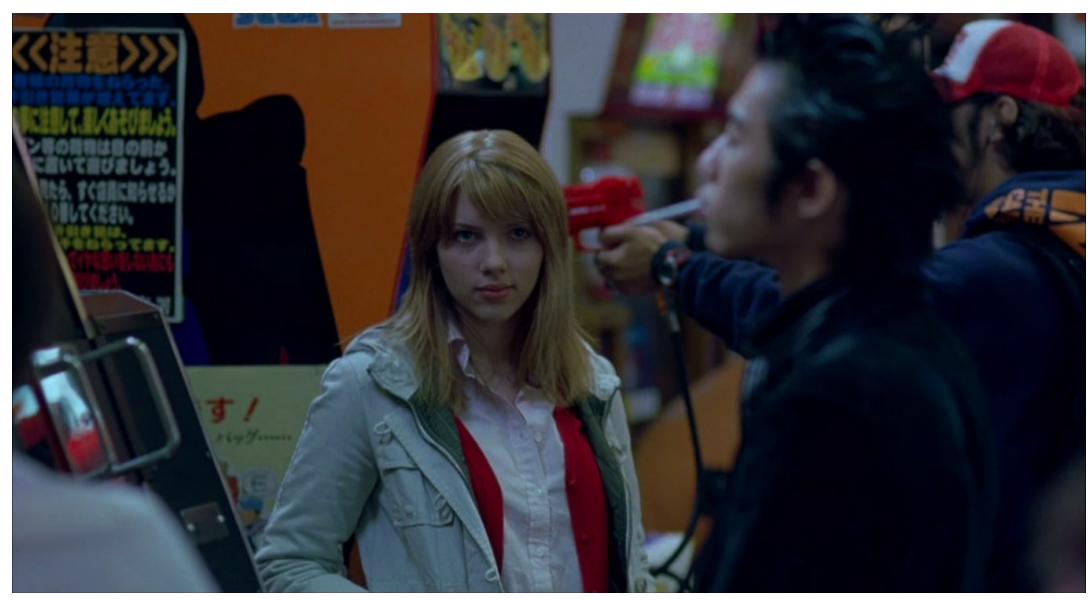

Lost in Translation. Fotograma de Charlotte observando a unos jóvenes japoneses mientras juegan. 
De lo que nunca es posible apropiarse -y lo que algunos dirían también es imposible de representar cinematográficamente en su totalidad- es de la ciudad en sí, la ciudad como esa mole inmensa donde ocurre todo simultáneamente, donde los senderos de vida de millones de personas se entrecruzan sin cesar. Lost in Translation ofrece una interpretación personal de esta idea, al presentarnos varias panorámicas del paisaje urbano en unas intermitencias poéticas cuya única funcionalidad es la evocación. En las panorámicas que siguen la contemplación de Charlotte, esta evocación está ligada a la experiencia de este personaje: su trance desde lo alto del hotel equivale a sus grandes aspiraciones de vida. En los planos medios que muestran las avenidas y carreteras de Tokio, ya al final del filme - cuando Bob va hacia el aeropuerto-, las panorámicas pretenden evocar la interioridad de Bob: la homogeneidad de los automóviles, el aspecto borroso de los neones y la canción Just Like Honey, de The Jesus and Mary Chain, equivalen a un sentimiento de pérdida o de nostalgia prematura hacia esa relación que acaba de terminar.

Pero hay otros planos amplios en los que la ciudad se presenta como una entidad indomable debido a su distancia y su magnitud. Aunque la cuestión aquí es preguntarse si en realidad hay otra manera de representar a Tokio al mismo tiempo que se abarca su envergadura. Stephen Barber nos explica que:

El Tokio empresarial y tecnológico que creció principalmente desde principios de los años setenta pulverizó los límites de la ambición arquitectónica, dando como resultado un espacio urbano excesivamente abigarrado, compuesto por una arquitectura que aglutinaba cualquier tendencia de la modernidad con un alto grado de alucinación ${ }^{14}$.

La ciudad de Tokio representada en Lost in Translation es realmente un facsímil de la metrópolis que pretende subrayar ciertos aspectos característicos de la misma. No es un acercamiento sumamente original -como los filmes que han lidiado con Tokio son «enfrentados a la casi total imposibilidad de representar la amplitud de ese cataclismo urbano, las películas contemporáneas de Tokio [...] suelen poseer una apariencia intercambiable, reducida a elemen-
[14] Stephen Barber, Ciudades proyectadas. Cine y espacio urbano (Barcelona, Gustavo Gili, 2006), p. 113 .
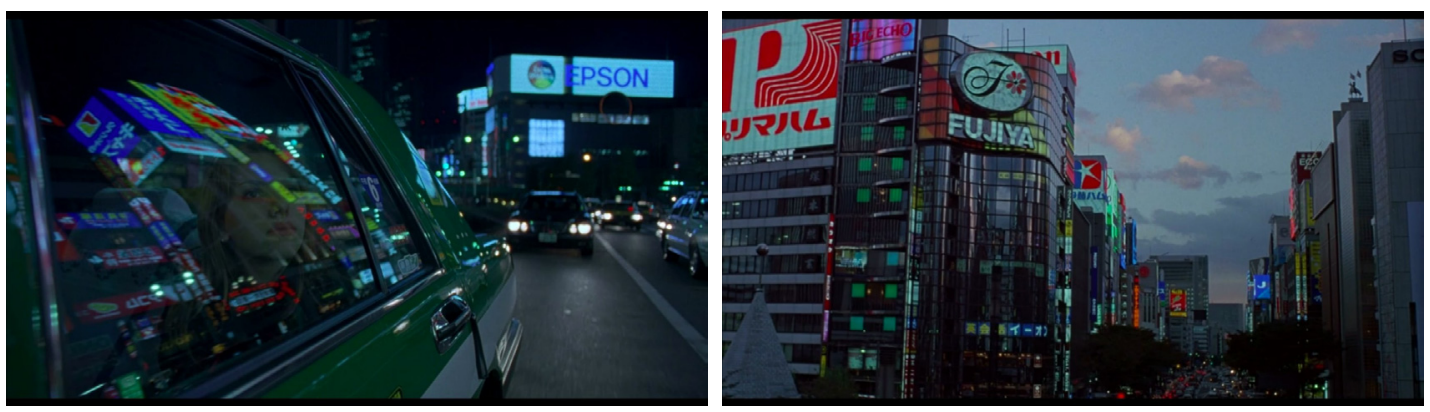

Lost in Translation. En el primer fotograma se imponen los símbolos urbanos de Tokio sobre el rostro de Charlotte; en el segundo se demuestra un paisaje urbano. 
tos homogéneos de alienación» ${ }^{15}$-, pero sí es un acercamiento que, llevado al nivel personal, es efectivo en su propósito.

Esto se debe a que el espacio fílmico en este largometraje no pretende ser más de lo que debe; funciona como elemento individual que le da un contexto a la acción, muestra las facetas físicas e incorpóreas de un espacio para crear un tono extendido y específico y exterioriza la psicología de los personajes mediante el paralelismo con los lugares antropológicos y mediante el contraste con los no-lugares-. Cuando Bob y Charlotte se sienten extáticos y tranquilos -las escenas del karaoke y la fiesta-, el espacio está allí para correr en paralelo a esa doble interioridad. Cuando se hallan solos en el seno de los no-lugares sucede lo contrario: su estado anímico se opone al tono del espacio, se niega a ser influenciado por él. Un par de ejemplos son el extravagante plató del programa de charlas al que atiende Bob, que es un espacio de humor y sandez que contrasta con el visaje de humillación que porta el personaje, y el metro de Tokio, que es un espacio hostil y frenético que contrasta con la templanza de Charlotte mientras intenta descifrarlo. Por esto es que «los dos protagonistas se encuentran desorientados, perdidos respecto a su propia vida, pero también en la ciudad. Tokio potencia su sensación de desamparo [...]. Todo en la gran metrópolis global les hace sentirse aún más pequeños y solos» ${ }^{16}$.

El proceso final de despersonalización presente en Lost in Translation tiene su apogeo en la historia de Bob. Prácticamente todos sus encuentros con el idioma japonés son exprimidos para extraer humor, así sea una interacción con la lengua hablada o con la lengua escrita. Durante el rodaje de su comercial de güisqui, durante la sesión fotográfica de promoción, durante la cena con Charlotte en el restaurante de sushi, durante su encuentro con la prostituta en su cuarto de hotel, durante el talk show al que es invitado, Bob se siente más y más alienado, configurado como una persona que simplemente no está hecha para entender la

[15] Stephen Barber, Ciudades proyectadas, p. 132.

[16] José Antonio Cerrillo Vidal, «Cine y experiencia urbana contemporánea», p. 9.

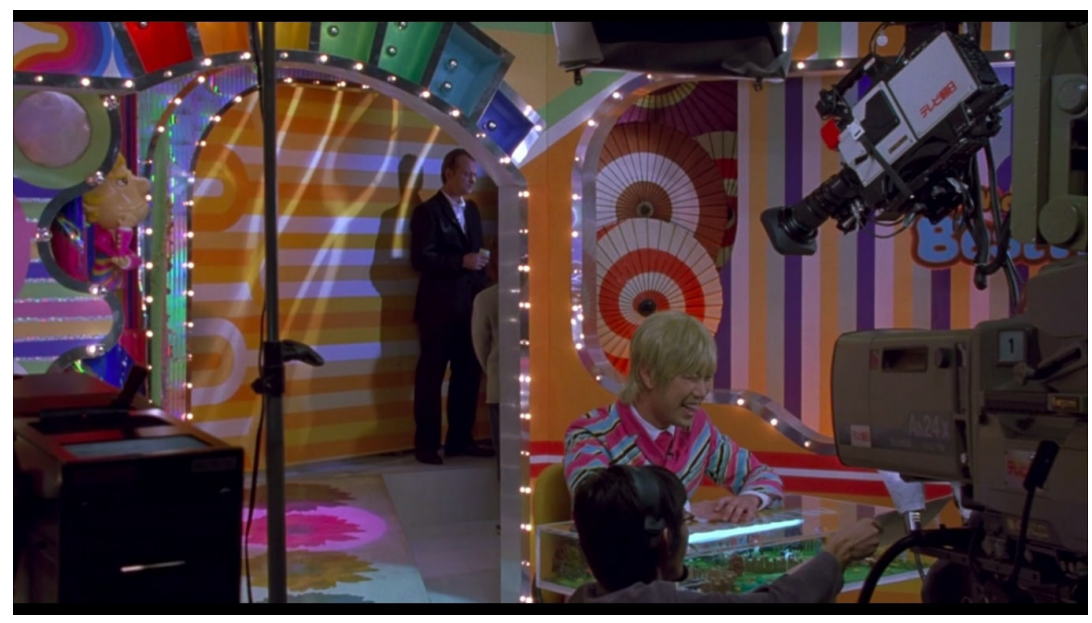

Lost in Translation. Bob esperando a ser llamado a plató. 
significación cultural japonesa ni para captar la sutil belleza de sus pormenores. Y es que «la burla de la cultura japonesa es continua: el personal del hotel que saluda obsesivamente a Bob, la ducha demasiado baja para su estatura occidental, la escena de la prostituta que no pronuncia bien en inglés, etc.» ${ }^{17}$. La barrera lingüística es utilizada de manera literal, como un obstáculo que convierte al extranjero en una especie de observador en un zoológico. Es bueno ver que también hay campo para el intercambio cuando se encuentra un referente común: durante la sesión de fotos, Bob y el fotógrafo, luego de un par de direcciones comunicadas torpemente, logran disfrutar un poco más de su situación después de que se menciona el Rat Pack.

Como punto final en esta consideración del espacio en Lost in Translation, me gustaría fijarme en la escena en la que Charlotte es testigo de una boda en Kyoto -o, más específicamente, de una caminata nupcial-. Encuentro relevancia en esta secuencia, porque en ella se concentra el choque cultural que experimenta Charlotte durante su visita al Japón: en ella somos nosotros los testigos de la desazón totalitaria que envuelve a este personaje. Su angustia central, que es la falta de propósito vital, se ve enfrentada, al desnudo, a una representación física del propósito, no solo a nivel personal, sino también a nivel cultural. La caminata nupcial, en la que los participantes están vestidos en ropa tradicional, es el Japón mostrándole a Charlotte lo que una vida satisfecha puede llegar a ser. Por esto es también relevante que dicha escena transcurra en un espacio que legitime la cualidad vetusta de la cultura japonesa: el espacio, junto con los que se desplazan en él, están en una perfecta armonía de perpetuidad, son partes adjuntas de un mismo acuerdo: la continuidad de la cultura. Charlotte, dudosa de su propio destino, no encaja en ese espacio.
[17] José Antonio Cerrillo Vidal, «Cine y experiencia urbana contemporánea», pp. 1-38.

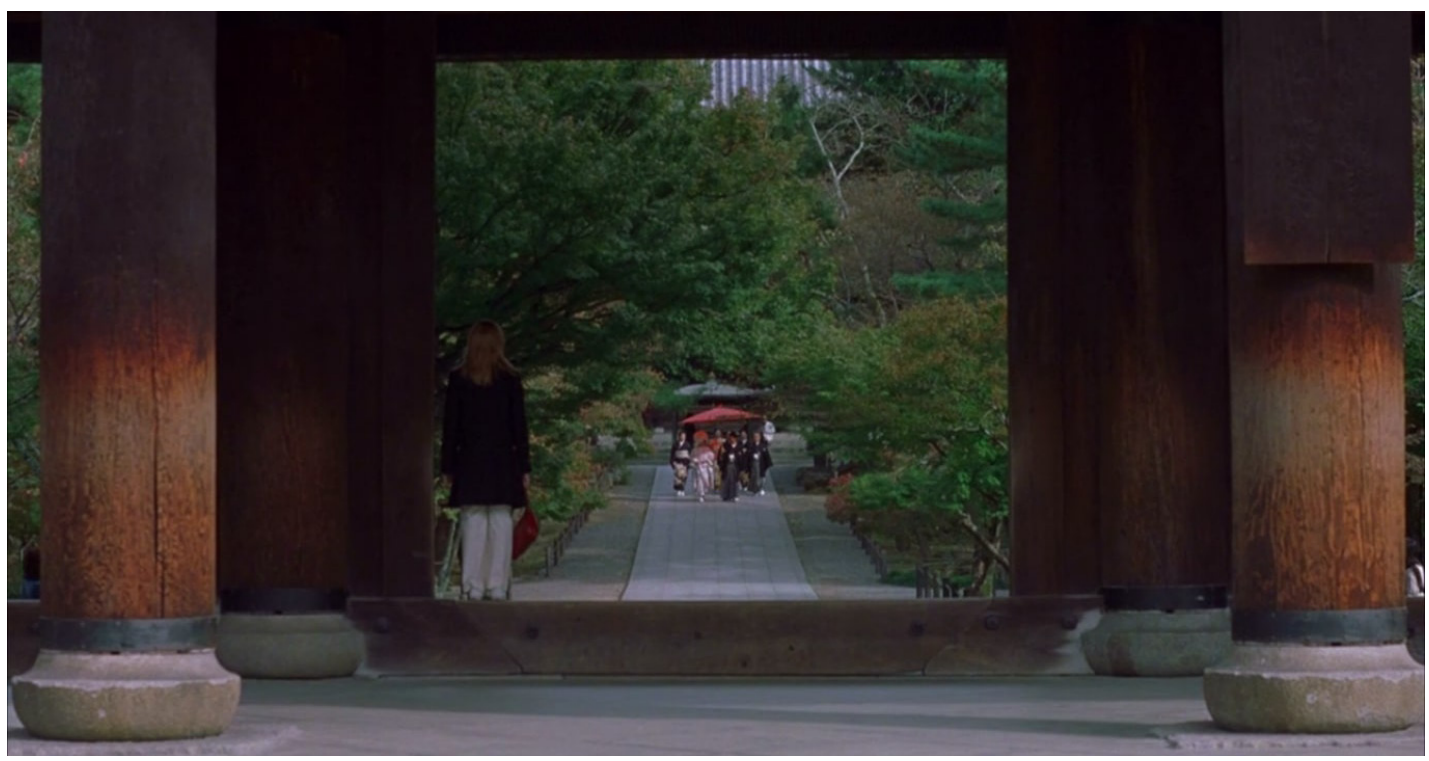

Lost in Translation. Charlotte observando atentamente la caminata nupcial de una pareja japonesa. 
[18] Stéphane Defoy, «Acteur convoité en quête de sens/ Somewhere de Sofia Coppola» (Ciné-bulles, vol. 29, n. ${ }^{\circ}$ 2, 2011), p. 58. (La traducción es mía).

[19] Apolline Caron-Ottavi, «Les limites du contrôle/Somewhere de Sofia Coppola» (24 images, vol. 151, 2011), p. 62. (La traducción es mía).
En completo contraste nos encontramos frente a Johnny Marco y su historia en Somewhere, siendo las naturalezas de la alienación y la despersonalización completamente diferentes, y, por la mayor parte de la duración del filme, no provenientes de una discordancia cultural. Esto es porque Johnny se encuentra en su país de origen, comparte su lengua materna con esa hablada en los espacios que habita y no es víctima de un deseo por explorar la ciudad. Y es que Coppola se preocupa, en este filme, por representar a su personaje principal en el epicentro de su soledad. «Ella no muestra nunca a su personaje mientras ejerce su profesión, prefiriendo el presentarlo deambulando en círculos en su cuarto de hotel, como un pájaro encerrado ${ }^{18}$. La audiencia ve a Johnny sobre todo en esos momentos privados en los que no vemos a nadie en la vida diaria - con la excepción de nosotros mismos-. Esto hace que Somewhere sea, de cierto modo, una experiencia voyerista centrada en los momentos nulos o tradicionalmente no representados en el cine - por ser vistos como innecesarios para el avance de la narración-, pero también en los íntimos y sexuales.

El perfecto ejemplo de esto ocurre en la habitación de Johnny en el Château Marmont, cuando la escena no se ocupa sino de presenciar el completo tedio del protagonista, que se encuentra sentado en un sillón, fumando y bebiendo cerveza. No sucede nada más, nada notorio. Pero es en el acto de representar algo que tradicionalmente no se ha considerado notorio donde Somewhere encuentra su legitimidad, su esencia como filme. Esta aproximación a la construcción fílmica, que logra con creces magnificar el atributo de mayor impacto en la formación de su personaje principal mediante las representaciones del espacio y la insistencia en el enfoque de esos instantes de monotonía, sufre, a pesar de todo, de una falta clara de dirección. Tal vez en su intento por mostrar la visceralidad del tedio, el filme termina por convertirse también en tedioso. Como opina Caron-Ottavi: «Somewhere recuerda a otro filme: The Limits of Control, de Jim Jarmusch. No se trata de compararlos, sino de subrayar el síntoma común que presentan: la exploración de un minimalismo remilgado donde la concatenación repetitiva de situaciones reemplaza toda progresión narrativa» ${ }^{19}$.

Una pieza clave en la representación espacial de este filme es la forma en que las relaciones interpersonales son presentadas en su contexto. A lo largo de la historia, vemos a Johnny disfrutar (dos veces) del espectáculo que montan unas gemelas nudistas que bailan en barra, lo vemos ser guiado por el espacio por una ayudante, lo vemos conduciendo su auto en círculos, en una rueda de prensa en la que promociona su último trabajo... Todas estas escenas comparten el mismo funcionamiento: el establecer los no-lugares como espacios donde la interacción humana es gobernada por el interés mercantil, por la ganancia monetaria, por la ilusión de la productividad laboral. Johnny, que tal vez solo sabe de esto a un nivel subconsciente, siente los efectos de este entretejido relacional e insustancial muy hondamente. ¿Quién puede culparlo? Su estatus como estrella de Hollywood no lo exime de verse perdido en la red omnipresente de asociaciones de interés productivo. Su angustia existencial 


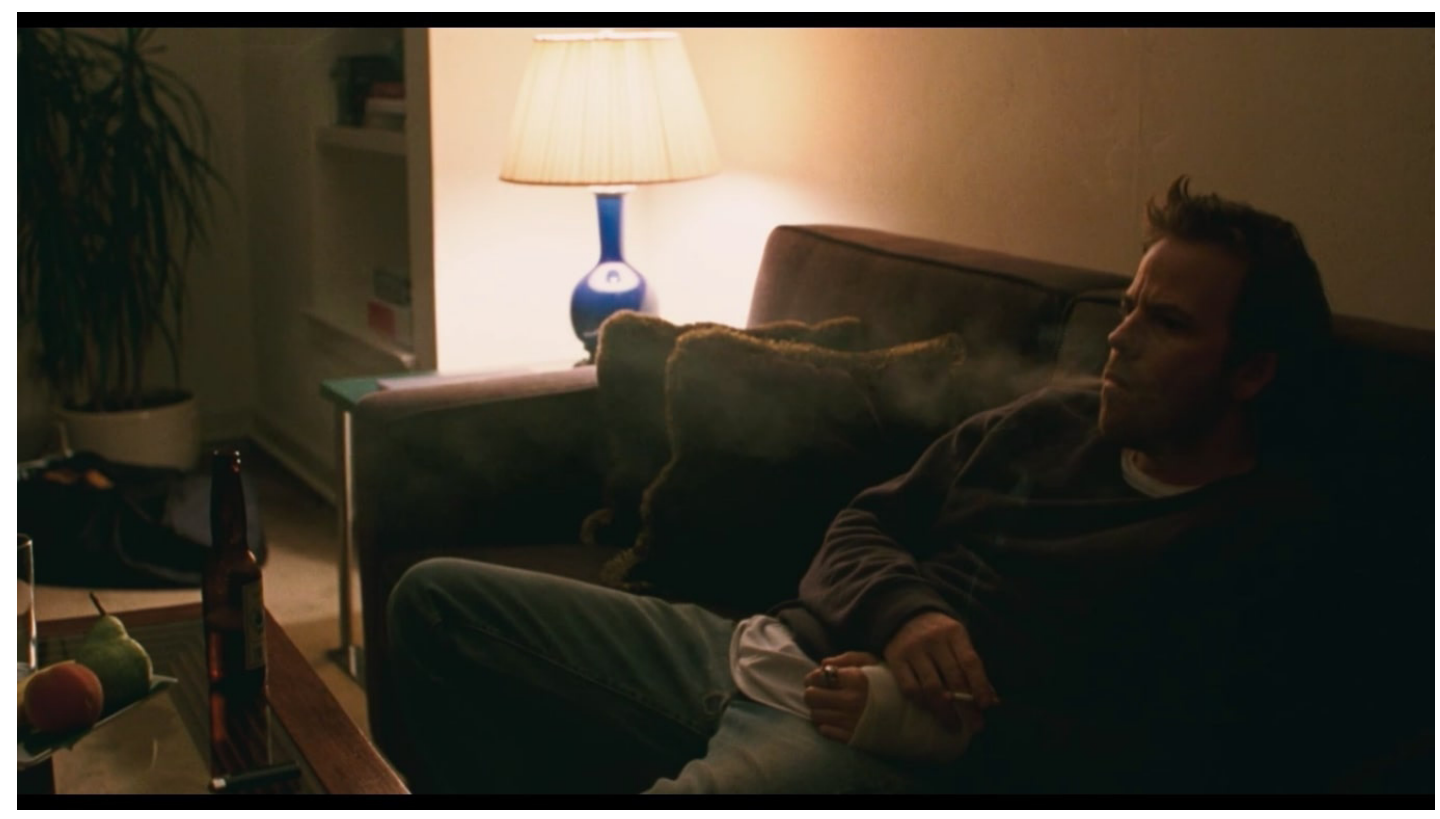

Somewhere (Sofia Coppola, 2010). Fotograma del tedio que sufre Johnny en su habitación del Château Marmont.

es engendrada por la falta de verdad en su cotidianidad; en un momento de lujuria, vemos a Johnny decirle a una mujer que acaba de conocer - mientras están los dos en la cama, a punto de quitarse la ropa- «kiss me, please». Una sentencia corta pero significante.

Esta supremacía del interés comercial sobre el interés humano en los espacios es típica de la Modernidad y está ligada al concepto del «espacio público» como lo discute Manuel Delgado:

El espacio público pasa a concebirse como la realización de un valor ideológico, lugar en el que se materializan diversas categorías abstractas como democracia, ciudadanía, convivencia, civismo, consenso y otros valores políticos hoy centrales, un proscenio en el que se desearía ver deslizarse a una ordenada masa de seres libres e iguales que emplea ese espacio para ir y venir de trabajar o de consumir y que, en sus ratos libres, pasean despreocupados por un paraíso de cortesía $^{20}$.

Delgado ve los conceptos actuales de «espacio público» y «ciudadano» como parte coercitiva del discurso hegemónico de las minorías dominantes en el sistema capitalista. Es decir, al estar estos dos conceptos ligados intrínsecamente a un eje político ${ }^{21}$ que pretende establecer normas de socialización excluyentes y que sirvan al desarrollo ramificado del capitalismo avanzado -en el sentido en que los ciudadanos están obligados a actuar bajo el umbral de lo cívico, concepto que inhabilita la resistencia y la apropiación de los espacios para funciones externas al sistema-, terminan por formar parte de la ideología dominante - tanto como manera sistemática de pensamiento como forma de [2o] Manuel Delgado, El espacio público como ideología (Madrid, La Catarata, 2011), p. 10.

[21] «El concepto de espacio público no se limita a expresar hoy una mera voluntad descriptiva, sino que vehicula una fuerte connotación política. Como concepto político, espacio público se supone que quiere decir esfera de coexistencia pacífica y armoniosa de lo heterogéneo de la sociedad». Manuel Delgado, El espacio público como ideología, p. 20. 
dominación física y mental- que intenta homogeneizar los conceptos de Estado y sociedad en su falsa búsqueda por la paz comunitaria.

Estas ideas están imbuidas en la representación espacial de Somewhere, ya que el concepto de Augé de los no-lugares coincide en muchos aspectos con aquel de espacio público de Delgado. Son aquellos espacios que el poder ha determinado aptos para el uso de todos los que terminan subyugados al funcionamiento comercial y los que dejan de ser espacios antropológicos para convertirse en no-lugares donde, para personas como Johnny Marco, es imposible quebrar la fachada de productividad de los conciudadanos para entablar una conexión humana que sobrepase la inmediatez. Esto se da también en Lost in Translation - piensen en la cordialidad excesiva que enfrenta Bob, por ejemplo-, pero, debido a su ángulo cultural, me pareció más oportuno mencionarlo en el contexto estadounidense, para resaltar el hecho de que, aun sin barreras de entendimiento cultural, los procesos de despersonalización se establecen en el espacio de la Modernidad de manera naturalizada. Además, esta discrepancia entre los deseos del individuo y el orden del espacio público se nota más agudamente en el personaje de Johnny, quien pasa de estar solo a experimentar el afuera siempre bajo los regímenes del civismo y la productividad.

Claro está que la presencia de su hija Cleo rompe con este esquema aparentemente interminable. Como se ha mencionado antes, Coppola abarca la emancipación en su visión como directora. Las escenas que comparten padre e hija, sobre todo las que suceden dentro del mismo espacio en el que escenas antes habíamos visto a Johnny rendirse ante el aburrimiento, son la prueba de que hay una manera de nivelar el campo de juego: apropiándose del espacio mediante la interrelación sincera y familiar. No solo Johnny siente la diferencia entre levantarse solo en ese cuarto de hotel y levantarse para encontrar que su hija le ha preparado un desayuno, la audiencia también lo siente. Pueden parecer cuestiones inocuas para el ojo frívolo, pero al fin y al cabo son cuestiones que nos conciernen a todos. ¿Qué hacer cuando «se instaura así una tierra de nadie, reino del consenso y la comunicación, cuyos habitantes llegan a acuerdos acerca de qué creer y qué hacer en cada situación» ${ }^{22}$ ? Naturalmente, tornarse hacia la creación de lazos familiares o de amistad.

Lastimosamente, Johhny Marco no es un personaje consciente de este poder redentor; ni siquiera en la escena en que Cleo practica su rutina de patinaje artístico, cuando Johnny llega, al parecer, a una revelación -de que su hija tiene una vida que va más allá de la que él conoce-, se acerca a esa sabiduría que tanto le habría ayudado a superar el tedio. En su lugar, Johnny ocupa su invasiva cotidianidad con una amplia variedad de vicios: además de la bebida y el tabaco, Johnny también se adentra en la prostitución y en los juegos de azar. Lo más punzante de esta situación es que, si se presta atención, no es difícil notar que Johnny cae en estas actividades casi por inercia, como si es-

[22] Manuel Delgado, El espacio público como ideología, p. 51. tuviera haciendo lo que él piensa que debería estar haciendo un actor famoso como él para pasar el tiempo y darle significado a su vida. Esto es un apartado 


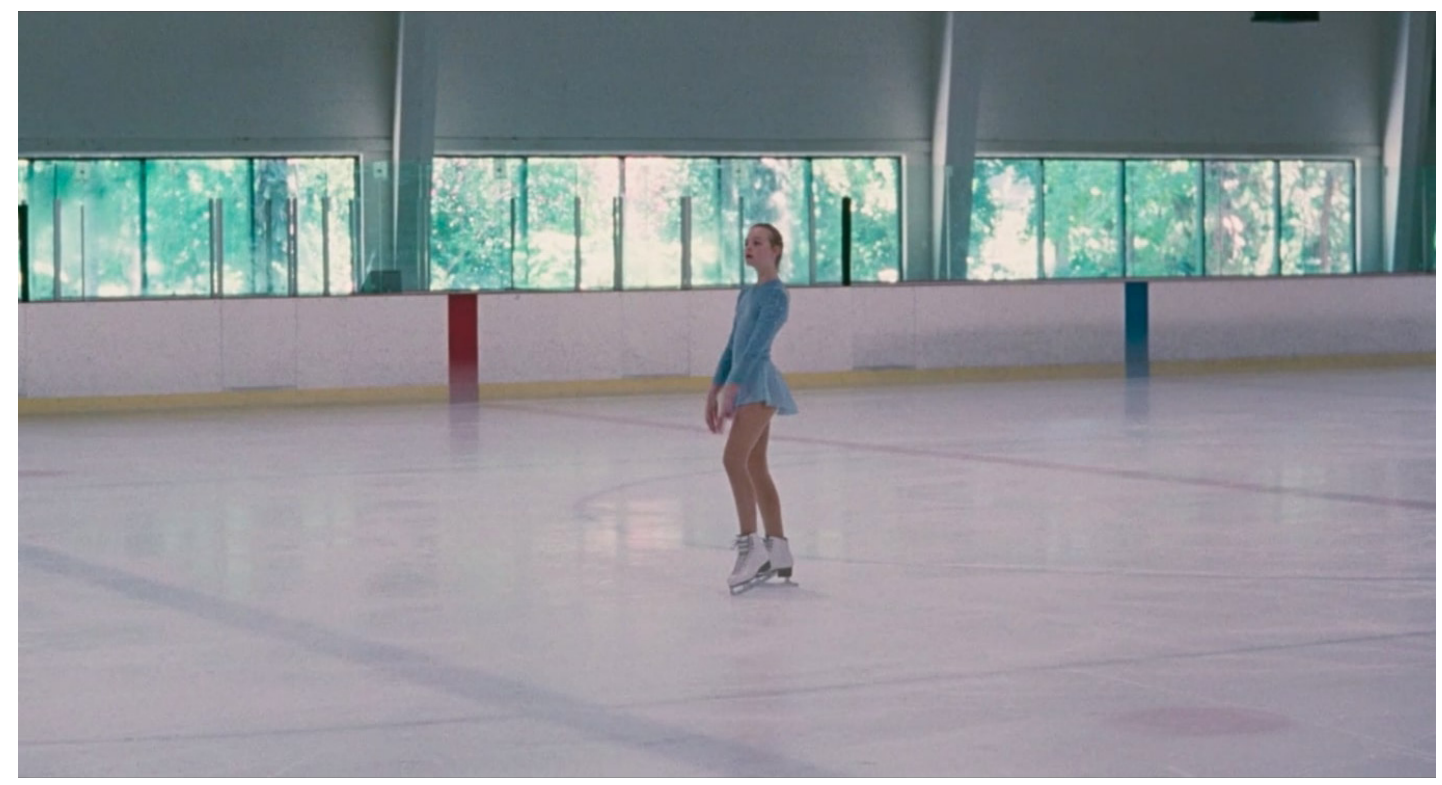

Somewhere. La pequeña Cléo practicando el patinaje artístico.

específico, limitado al mundo hollywodiense y sus funciones endogámicas, de la actitud del ciudadano en el espacio público: el hacer porque se cree que se debe hacer.

Pero, si no es el espacio en sí el que causa la alienación, como se pretende sostener en este trabajo, ¿̇cuál sería la verdadera causa? Saltando del concepto previo de la mansedumbre del ciudadano, apoyémonos en la teoría sociológica de David Riesman para aclarar esta cuestión. Riesman, en su famosa obra La muchedumbre solitaria (1950), nos explica lo que es para él el «carácter social»:

[...] En este sentido, carácter es la organización más o menos permanente, social e históricamente condicionada, de los impulsos y satisfacciones de un individuo, la clase de «equipo» con que enfrenta al mundo y la gente. «Carácter social» es aquella parte del «carácter» que comparten los grupos sociales significativos y que, tal como casi todos los científicos sociales contemporáneos lo definen, constituye el producto de la experiencia de esos grupos ${ }^{23}$.

El carácter social es lo que nos lleva a buscar la conformidad dentro de la sociedad que habitamos, es ese sentimiento de pertenencia al grupo que todos experimentamos al ser seres sociales. Riesman luego prosigue a definir tres tipos de carácter social, entre los cuales nos interesa el denominado carácter social «definido por los otros». Este surge en las poblaciones de alto nivel de desarrollo y de poca declinación demográfica, y su «conformidad está asegurada por su tendencia a ser sensibles a las expectativas y preferencias de los otros» ${ }^{24}$. También típico de la Modernidad, este carácter social juega un papel

[23] David Riesman, Revel Denney y Nathan Glazer, La muchedumbre solitaria (Barcelona, Paidós, 1981), p. 16.

[24] David Riesman et al., $\mathrm{La}$ muchedumbre solitaria, pp. 21-22. 
central en la naturaleza del choque de Johnny Marco con su realidad circundante. Así como Charlotte en su respectivo filme, Johnny es capaz de intuir que su búsqueda de propósito está guiada por la conformidad, por el deseo de llevar un ritmo de vida normal en el que no quepan dudas existenciales y se funcione como parece que funcionan todos los demás miembros de la sociedad. Su mayor choque es la realización - no completamente cognoscible por ellos mismos en su desarrollo- de su complicidad en su propia alienación.

A todo esto se acerca la visión coppoliana en Somewhere al representar los espacios por los que se mueve Johnny. En este filme ni siquiera hay un intento por representar a la ciudad de Los Ángeles como un todo, así como hay en Lost in Translation con Tokio. El enfoque ya no es la ciudad como espacio que acrecienta la soledad de la Modernidad, sino aquellos fragmentos del espacio -llamémoslos no-lugares primero, espacio público después-que sirven para fermentar aquellas semillas de alienación plantadas en el ser humano por las normativas de su carácter social, las discrepancias personales entre sus ambiciones y su capacidad para cumplirlas y demás factores de despersonalización del sistema capitalista hegemónico.

Una escena brillante que ejemplifica esta idea en el largometraje, y que seguramente le pasará por alto a la mayoría de espectadores gracias a la magia del montaje cinematográfico, es la de los aeropuertos: en un momento de la historia, Johnny y Cleo se disponen a viajar de Los Ángeles a Italia, por lo cual son conducidos por un chófer hasta el aeropuerto internacional de la ciudad californiana (LAX). Padre e hija entran, con un andar un poco ansioso, mientras son escoltados por varios hombres. La próxima imagen es de ellos saliendo de un aeropuerto. La diferencia aquí es que los nuevos escoltas les hablan en italiano y se toman una foto con Johnny. Hemos pasado fluidamente de un país a otro gracias a la homogeneidad y falta de ánima de los no-lugares. El espacio de los dos aeropuertos sirve como puente hablando en términos del montaje, pero también resalta la falta de color o de espíritu de estos espacios. Al igual que con su cuarto de hotel, Johnny no puede apropiarse de este tipo de espacios por sí solo y está condenado a descender en espiral mientras los habita.
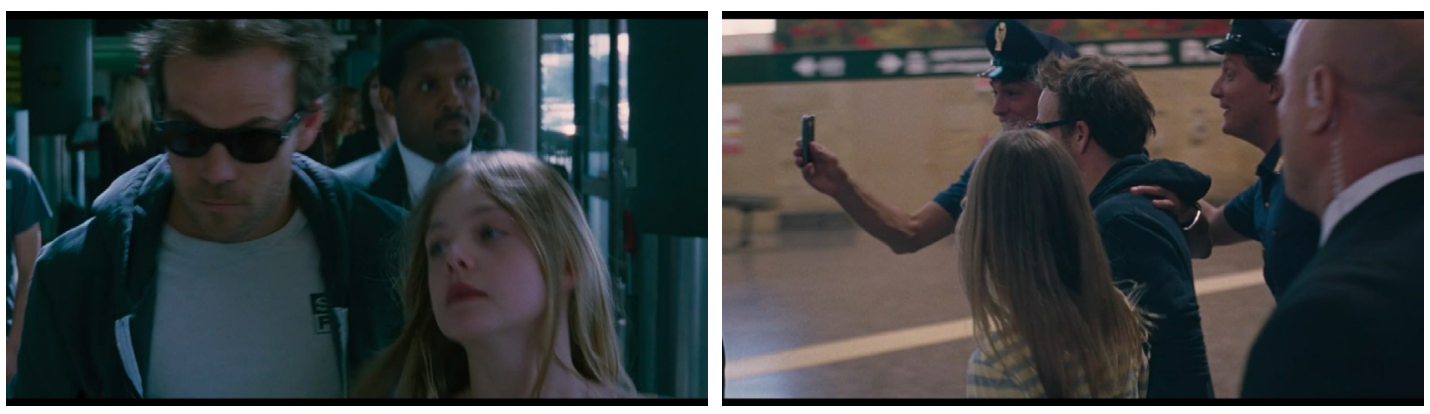

Somewhere. En el primer fotograma se ve a padre e hija en LAX, antes de abordar. En el segundo han sido transportados a Italia, y vemos a unos hombres queriendo tomarse un selfie con Johnny. 
Su salvación fue el hecho de haber tenido que cuidar de su hija. Esto está demostrado a lo largo del filme, de manera moderada. Por un lado, están los pequeños momentos que comparten padre e hija, que mayormente se ocupan del juego: juegan Guitar Hero, juegan al ping-pong, juegan con naipes y juegan en la piscina. Todas estas acciones están enmarcadas en el espacio del hotel -el Château Marmont y su hotel en Italia-, el cual parecía succionar todo el alborozo y la energía de Johnny cuando lo habitaba solo. Vemos en estas escenas de la película la exploración de un proceso de apropiación del espacio: el juego -seguramente porque los juegos facilitan las interacciones y aumentan la confianza entre los participantes-. Por otro lado, más moderado y simbólico, está la figura del automóvil, espacio poco convencional cuando se piensa directamente en el concepto de no-lugar. Y es que el auto de Johnny funciona visualmente para representar su estado emocional al comienzo y al final del filme y para abarcar la evolución de amor paterno-filial que enciende su fuego emancipador. Respecto a la primera función, la descripción de las escenas mismas sirve de explicación suficiente: la primera escena demuestra al auto dando vueltas en una pista de tierra; la última muestra a Johnny dejando su auto atrás mientras camina por un sendero pavimentado en el campo. Sobre la segunda función del automóvil, vale la pena decir que Johnny y Cleo desarrollan en él su relación: el espacio del auto y de lo que representa es apropiado -y, en últimas, abandonado- a medida que avanza la trama.
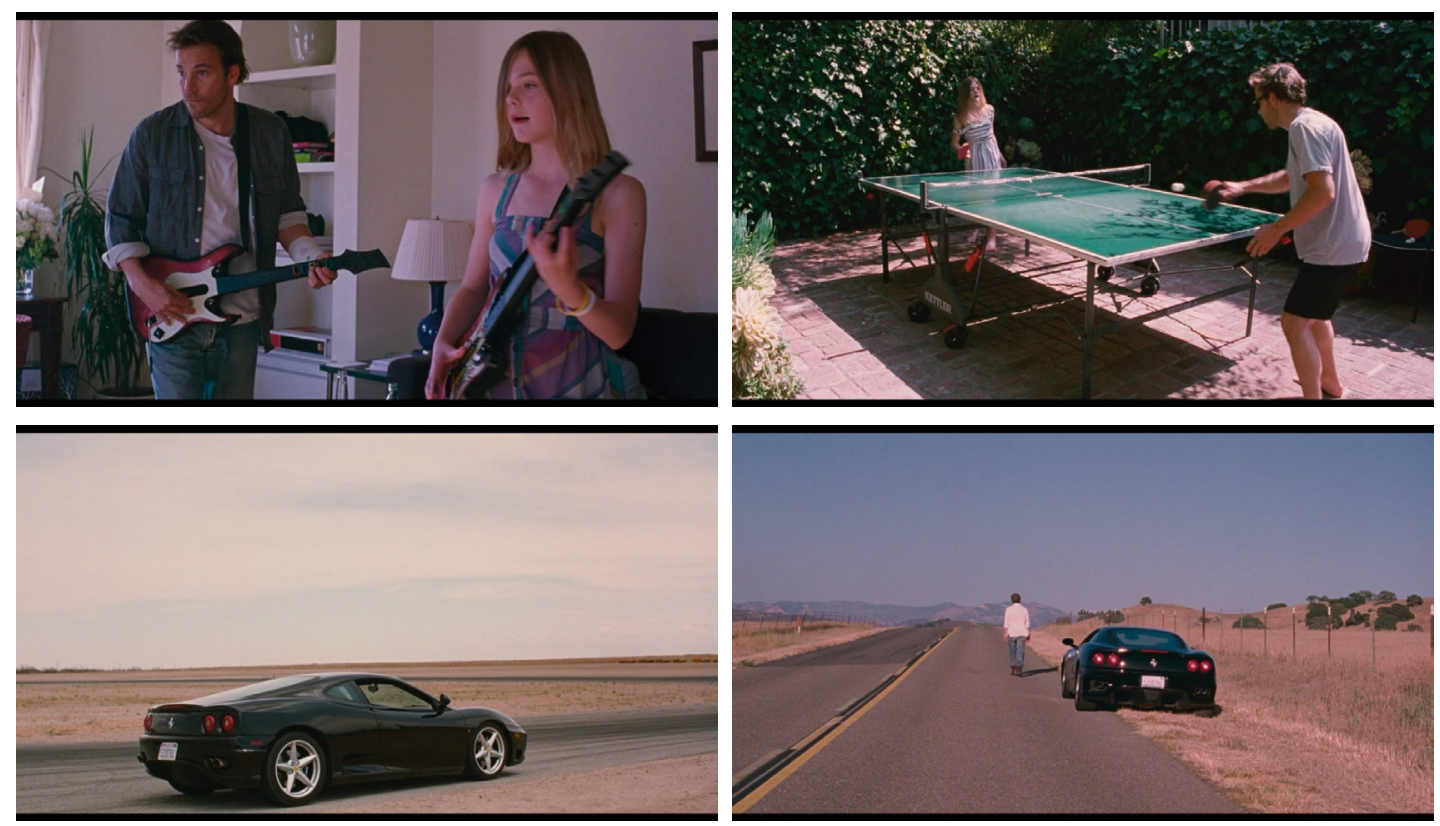

Somewhere. Los primeros dos fotogramas demuestran la intimidad paterno-filial conseguida mediante el juego. El tercero ocurre al inicio del filme y nos introduce a los espacios desahuciados de Los Angeles. El último ocurre justo al final y sirve como aliento esperanzador luego de enfrentarse de lleno al no-lugar. 
[25] Fabien Demangeot, «L'esthétique du vide dans le cinéma de Sofia Coppola» (Studia Universitatis Petru Maior - Philologia, vol. 19, 2015), p. 102. (La traducción es mía).

[26] Fabien Demangeot, «L'esthétique du vide dans le cinéma de Sofia Coppola», p. 102. (La traducción es mía).
Esta capacidad que tienen los afectados de otorgarle al no-lugar un nuevo propósito es algo que tienen en común los dos largometrajes. Esto es también lo que me incita a creer que el espacio fílmico, tal cual fue diseñado por la directora, tiene menos una función dominante que de exteriorización. Sobre todo en la figura del hotel. Como nos lo explica Fabien Demangeot:

En Somewhere, Johnny pasa gran parte de su tiempo en el Château Marmont [...]. Sin embargo, es en el seno de este mismo hotel que Johnny reanudará una relación afectiva sólida con su hija. Los hoteles de Lost in Translation y Somewhere no son lugares cerrados. Ellos no impiden que los personajes exploren el mundo. Ellos se presentan, ante todo, como espacios de reposo y de reflexión. La meditación de Charlotte, sola en su habitación, es el ejemplo más contundente. El espacio es un objeto paradójico que, sin embargo, siempre sirve como metáfora de los estados psíquicos ${ }^{25}$.

Lo que no se deja tan claro es la permanencia de esta emancipación, dada la naturaleza paradójica y efusiva de la apropiación. Entre Bob y Charlotte, como entre Johnny y Cleo, hay una separación dolorosa que pone en tela de juicio todo lo que habían construido juntos, en el seno de los no-lugares que los juntó en primera instancia. «Las lágrimas de Cléo cuando le dice adiós a su padre hacen, evidentemente, eco a las de Charlotte, durante el final de Lost in Translation. La partida de Italia de Somewhere, como las despedidas de Bob en Lost in Translation, anuncian una separación ineluctable» ${ }^{26}$. He aquí algo que pareciera une a los dos filmes de Coppola: una ruptura abrupta y entristecida entre los protagonistas que destruye su previo intento por hallar significado entre los espacios de la Modernidad.

La gran diferencia entre los dos filmes es el final: Lost in Translation separa a los protagonistas - de una manera que es fácil de entender como permanente-, quienes podían aún servirse de su compañía para alcanzar otro estrato de satisfacción vital que no dependiera del cumplimiento de responsabilidades familiares o económicas en la medida en que formarían un vínculo no delimitado por las necesidades sociales. Somewhere, aunque también separa a Johnny de su hija, le da una salida al protagonista al encuadrarlo sobre un sendero de campo - apto símbolo de libertad, en contraste con lo que sería un símbolo de rutina y conformismo: una carretera urbana en Los Ángeles-y dejándolo marchar fuera de su automóvil sin un rumbo fijo, pero con la esperanza de que su existir adquirirá sentido en el deambular. Esta acción es diametralmente opuesta al funcionamiento social de las personas dirigidas por los otros $-\mathrm{y}$, hablando en términos generales, de la gente moderna que vive desplazándose más que todo por un sinfín de no-lugares que se concatenan para perpetuar la ilusión de un espacio público en el que no hay desigualdad y en el que reinan las pautas del consumo, tirano del significado humano en la contemporaneidad-, que únicamente buscan el definir su ánima mediante la comparación para con sus iguales.

Es en este aspecto en el que triunfa Coppola, al ser su construcción y representación del espacio fílmico sumamente eficaz en el exteriorizar la alie- 
nación de sus protagonistas. Algo importante, considerando que «en un filme narrativo, el mecanismo para construir una historia coherente de lo que vemos y oímos nos conducirá a buscar indicios espaciales específicos y basarnos en esquemas espaciales específicos» ${ }^{27}$. Como espectadores, buscamos y hallamos una razón contextual que justifique la continuación indiscriminada de este par de problemáticas del espíritu que asedian las almas de los personajes y, gracias a la detallada construcción del espacio fílmico, logramos, hasta cierto punto, creer en ese impalpable sufrimiento. Creemos en él porque hay una buena demostración de procesos de despersonalización en el espacio, aunque, gracias al enfoque en la interacción humana, no le cedemos el honor de la causa.

Es así, recordando que «el cine narrativo intenta transformar el espacio -más o menos indiferenciado, simple resultado de las propiedades miméticas básicas del aparato fílmico- en lugar, es decir un espacio vectorizado, estructurado, organizado según la ficción que se desarrolla» ${ }^{28}$, que podemos decir que los espacios representados en Lost in Translation y Somewhere son, primero que todo, agentes de influencia secundaria en la alienación y en la despersonalización de los personajes - gracias a su estado de subyugación ante su funcionalidad narrativa- $\mathrm{y}$, de manera accesoria, representativos de las problemáticas presentes en la Modernidad, paradójicamente los mismos espacios donde se puede conseguir la emancipación. Su nivel de cercanía a la contemporaneidad en la que existen tal vez se pierda con el tiempo, pero, en el momento en que esto se escribe, el espacio fílmico construido por Coppola en las dos películas ilustra un sinfín de afecciones reales en las que el espacio juega un papel más fuerte que el que juega en la ficción.

\section{Bibliografía}

Augé, Marc, Non-lieux Introduction à une anthropologie de la surmodernité (París, Éditions du Seuil, 1992).

Aumont, Jacques y Marie, Michel, Análisis del film (Barcelona, Paidós, 1990).

BARBEr, Stephen, Ciudades proyectadas. Cine y espacio urbano, (Barcelona, Gustavo Gili, 2006).

BordWELL, David, La narración en el cine de ficción (Barcelona, Paidós, 1996).

Caron-Ottavi, Apolline, «Les limites du contrôle/Somewhere de Sofia Coppola» (24 images, vol. 151, 2011), p. 62.

Cerrillo Vidal, José Antonio, «Cine y experiencia urbana contemporánea» (Aposta revista de ciencias sociales, $\left.\mathrm{n} .^{\circ} 43,2009\right)$, pp. 1-38.

Defoy, Stéphane, «Acteur convoité en quête de sens/Somewhere de Sofia Coppola» (Ciné-bulles, vol. 29, n. ${ }^{\circ}$ 2, 2011), p. 58.

Deleuze, Gilles, L’image-mouvement (París, Éditions de minuit, 1983).

Delgado, Manuel, El espacio público como ideología (Madrid, La Catarata, 2011).

Demangeot, Fabien, «L'esthétique du vide dans le cinéma de Sofia Coppola» (Studia Universitatis Petru Maior - Philologia, vol. 19, 2015), pp. 98-104.

FrISBY, David, Paisajes urbanos de la modernidad Exploraciones críticas (Buenos Aires, Prometeo Libros, 2007).
[27] David Bordwell, La narración en el cine de ficción, p. 104.

[28] Jacques Aumont, «L'espace et la matière», Théorie du film (París, Albatros, 1980), citado por Aumont y Michel Marie, Análisis del film, (Barcelona, Paidós, 1990), p. 189. 
Moraes Cavalcante, Denise, «Entre o hotel e a cidade: espaços em trânsito no filme Encontros e desencontros da diretora Sofia Coppola» (Comunicación: revista Internacional de Comunicación Audiovisual, Publicidad y Estudios Culturales, n. ${ }^{\circ}$ 10, 2012), pp. 412-427.

PAZ OTERo, Héctor, «El cine de Sofía Coppola: la deconstrucción de la mirada patriarcal» (Quaderns de cine, n. ${ }^{\circ}$ 5, 2010), pp. 71-76.

Riesman, David, Denney, Revel y Glazer, Nathan, La muchedumbre solitaria (Barcelona, Paidós, 1981).

Recibido: 12 de septiembre de 2018

Aceptado para revisión por pares: 11 de enero de 2019

Aceptado para publicación: 21 de septiembre de 2020 
